\title{
Effects of sintering schedule on the characteristics of Fe-based powder compacts formed through warm compaction route
}

\author{
M.M. Rahman ${ }^{1 *}$, M.H. Rosli ${ }^{1}$ and D. Namasivayam ${ }^{1}$ \\ ${ }^{1}$ Centre for Advanced Materials, College of Engineering, \\ Universiti Tenaga Nasional, Putrajaya Campus, 43000 Kajang, Selangor, Malaysia, \\ "E-mail: mujibur@uniten.edu.my \\ Phone: +60389287269; Fax: +60389212116
}

\begin{abstract}
This paper presents the sintering characteristics of Fe-based powder compacts formed through the warm compaction method. Iron powder ASC100.29 (73 wt\%), chromium powder $(22 \mathrm{wt} \%)$, and aluminium powder $(5 \mathrm{wt} \%)$ were mixed mechanically for $60 \mathrm{mins}$ in preparing the feedstock. The powder mixture was subsequently compacted at $200^{\circ} \mathrm{C}$ through simultaneous loading of $325 \mathrm{MPa}$ from upper and lower punches. The defectfree green compacts were then sintered in an argon gas fired furnace at a rate of $10^{\circ} \mathrm{C} / \mathrm{min}$ by varying the sintering time $(30,60$, and $90 \mathrm{mins})$ and temperature $(600,750$, and $900^{\circ} \mathrm{C}$ ), respectively. The sintered samples were characterized through physical and mechanical properties and their microstructures were analysed through scanning electron microscopy. The results revealed that sintering at $900^{\circ} \mathrm{C}$ for 90 mins contributed to the highest volumetric expansion and relative density change, which are not expected in the powder metallurgy industries. A moderate sintering temperature of $750^{\circ} \mathrm{C}$ for a holding time of 60 mins was found to produce a sintered sample with higher bending strength. In these sintering conditions, better dispersion of the alloyed elements is also observed.
\end{abstract}

Keywords: Warm compaction; sintering temperature; holding time; physical and mechanical properties.

\section{INTRODUCTION}

Pure metals are usually weak and soft at high temperature due to their ductility and malleability $[1,2]$. Therefore, by imparting some alloying elements into the pure metals, alloys are formed. An alloy is the combination of two or more metallic elements to form a mixture of solid solution. Alloys are stronger, harder, and have good corrosion resistance under severe conditions [3]. FeCrAl alloy is one of the super alloys with high temperature and oxidation resistance. $\mathrm{FeCrAl}$ alloy is widely applicable in heating industries, where it serves in heating elements of industrial furnaces, rheostats, emergent heaters and ceramic electric pots. Current practice for forming $\mathrm{FeCrAl}$ alloy or any other alloy is either through a foundry process or by mechanical alloying . [4, 5] Forming of $\mathrm{FeCrAl}$ alloy through a foundry process requires a huge quantity of thermal energy to melt the billets of pure iron $(\mathrm{Fe})$ and the other alloying elements, i.e., chromium $(\mathrm{Cr})$ and aluminium (Al). The foundry process can produce only alloy billets, which then require a series of further metal forming steps, i.e., casting, forging, machining, surface finishing, etc. to produce an end-product. On the other hand, mechanical alloying can be used to form a solid solution in a small volume in powder form, which also requires a lengthy series of further processing steps to produce an end-product [6]. 
It is evident from the brief explanation above that both alloying methods are timeconsuming, energy-inefficient, and hence expensive [7, 8]. Another possibility is the simultaneous forming of $\mathrm{FeCrAl}$ alloy and production of end-products through powder mixing, shaping at above room temperature, and sintering in a controlled environment, which is termed the warm powder compaction process [2]. This technique is relatively new but offers an approach to produce net-shape yet high quality products without machining and surface finishing [9]. Warm powder compaction technology has advanced significantly over the past decades [9] and is considered as an alternative lower-cost process to machining, casting, stamping, forging and other similar metal-working technologies [10]. The metal powder is believed to experience softening [11] when formed at elevated temperature, which is considered as a major factor in improving the rearrangement of particles as well as their flow, thus reducing the interconnected pores and hence increasing the strength of the products [12]. The basic principle of sintering is achieving the desired degree of bonding among the particles in powder compacts [13]. The heating and cooling rate, sintering temperature, and holding time play important roles in controlling the microstructure and porosity that determine the degree of particles bonding. In solid state sintering, the bonding among particles requires material transport by volume diffusion (migration of vacancies), grain-boundary diffusion, surface diffusion, viscous or plastic flow, and evaporation/condensation of atoms on the surfaces [14]. The densification and the strengthening of particles inside the metal powder compact reflect the properties of the sintered components [15]. The sintered density relates directly to the dimensional and mass changes, which give a perfect understanding of the densification process [16]. Most importantly, the relative density of sintered parts determines the porosity. The sintered strength and hardness indicate the degree of particles bonding and the particles arrangement at the surface of the compact, respectively [17].

Attempts to form alloys and manufacture end-products simultaneously through powder metallurgy were first made a long time ago [18]. However, progress has been very slow due to the immiscibility of some materials below the recrystallization temperature of the individual materials. Recently, simultaneous alloy forming and endproduct manufacturing through the warm powder compaction route has been reported in $[19,20]$. A full cycle of warm powder compaction consists of feedstock preparation, heating of the powder mass and die assembly, compaction of the powder mass in the desired shape at the preset temperature, ejection of the shaped compacts from the die cavity, termed as green compacts, and finally sintering the green compacts in a controlled environment [21]. However, feedstock preparation, powder shaping, and sintering are the three main steps in a full cycle of the powder compaction process. Feedstock preparation means the mixing of the main powder constituent together with other alloying elements and additives/lubricants in a low-speed mixer to make a coherent powder mass that is ready to be compacted [22]. Powder shaping is crucial since it determines the quality of the green compacts. A proper axial load must be applied to the powder mass in order to compact it according to the desired shape. Too much load causes the initiation of microcracks inside the green compacts, which may cause the failure of the products after sintering. However, insufficient load also reduces the strength of the green products, which may be difficult for the further handling of the products [23]. The use of a lubricant could minimize interparticle and die wall frictions during ejection, which ultimately enables the production of green compacts without any significant defect $[24,25]$.

The last step in a full cycle of powder compaction is the sintering, which is usually conducted at a temperature that is $60-70 \%$ of the melting point of the main powder 
constituent [26]. Several studies have been conducted related to the sintering of powder metallurgy green compacts produced either through injection moulding [27] or through powder compaction [2]. In injection moulding, there is an additional step, which is to remove the binders prior to sintering, which is termed as debinding. However, green compacts generated through either cold or warm powder compaction can be sintered directly after ejection from the die cavity since the lubricant content is very small, i.e., less than $0.5 \%$ [14]. Most of the reported studies on powder compaction were to produce components from a single metal or ceramic powder [28]. Few works have reported on the forming of alloy and manufacturing components simultaneously through the powder compaction process except for those reported in $[2,17,20]$. Therefore, the objective of this paper is to present the outcome of an experimental investigation of the effects of sintering parameters, especially the sintering temperature warm compaction process.
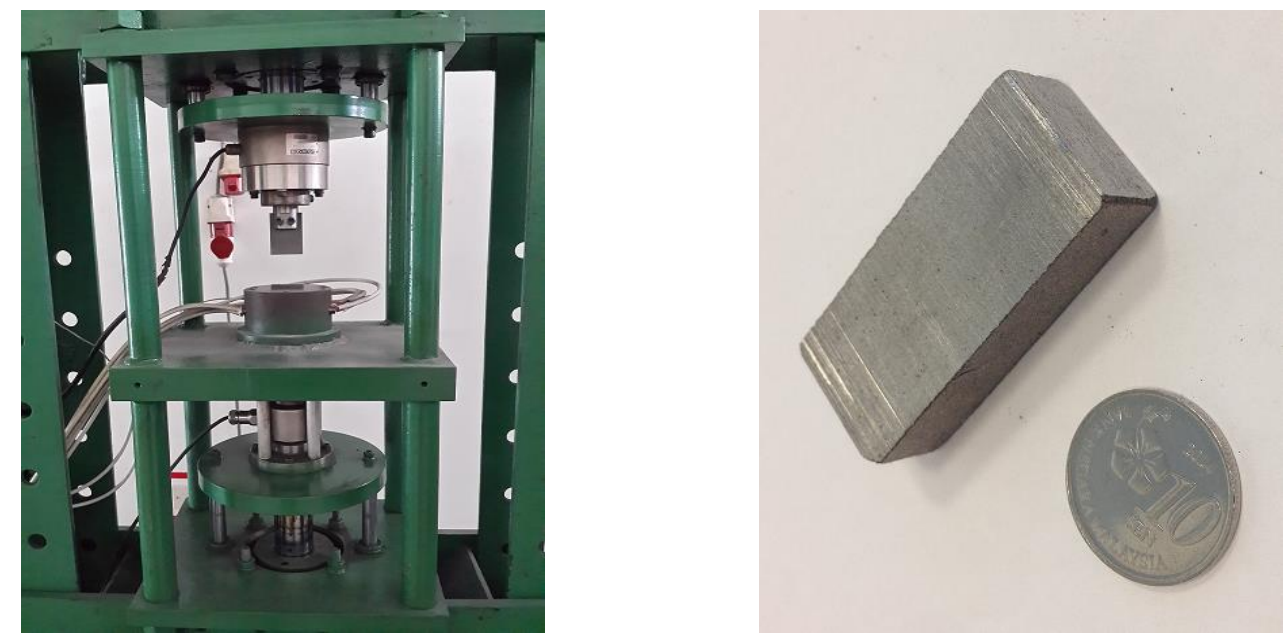

Figure 1. (a) T-15 compaction rig with heating system, (b) as-pressed sample.

\section{MATERIALS AND METHOD}

The experimental procedure consists of four steps: (i) powder mass preparation or mixing of iron powder with other alloying elements, (ii) green sample generation, (iii) sintering in an argon gas fired furnace at different schedules, and (iv) sintered sample characterization. Iron powder ASC 100.29 of 20-180 $\mu \mathrm{m}$ particle size range was used as the main powder constituent. The chromium $(\mathrm{Cr})$ content was $22 \mathrm{wt} \%$, aluminium content was $5 \mathrm{wt} \%$, and the balance $(73 \mathrm{wt} \%)$ was iron powder. The main powder constituents, i.e., $\mathrm{Fe}$ and the alloying elements $(\mathrm{Cr}$ and $\mathrm{Al})$, were mixed mechanically for 60 mins. The powder mass was filled into the rectangular die cavity $\left(40 \times 10 \times 15 \mathrm{~mm}^{3}\right)$, then all the die were assembled together and the powder mass was heated up to $200^{\circ} \mathrm{C}$ and kept for 30 mins for uniform heating of the powder mass and the die assembly. The filled powder mass (mixture of $\mathrm{Fe}, \mathrm{Cr}, \mathrm{Al}$ ) inside the die cavity was compacted by an axial pressure of $325 \mathrm{MPa}$ simultaneously from upper and lower punches (Figure 1(a)) by using a custom-made $15 \mathrm{~T}$ compaction machine. The as-pressed samples, termed as green compacts (Figure 1(b)), were inspected visually for any defects and the defect-free green compacts were subsequently sintered using a custom-made argon gas fired sintering furnace (HT3-1400-SIC) at a rate of $10^{\circ} \mathrm{C} / \mathrm{min}$ for three different holding times, namely 30,60 , and 90 mins. All the samples were sintered at $600^{\circ} \mathrm{C}, 750^{\circ} \mathrm{C}$, and $900^{\circ} \mathrm{C}$, respectively. The sintered samples were characterized for their physical (volumetric expansion and relative density compared to the green samples) and mechanical properties 
(bending strength, ASTM E290-09) and their microstructures were evaluated using scanning electron microscopy (SEM).

\section{RESULTS AND DISCUSSION}

The volumetric expansion is found to have an increasing effect with the ascending sintering temperature. This can be seen in Figure 2, where the highest volumetric expansion was obtained by the sample sintered at $900^{\circ} \mathrm{C}$. Although the volumetric expansion escalated with the sintering temperature, there is a slight drop of volumetric expansion of the sample sintered at $750^{\circ} \mathrm{C}$ for 30 mins, which is $4.91 \%$ when compared to the sample sintered at $600^{\circ} \mathrm{C}$ for $30 \mathrm{mins}$, which was $5.58 \%$. The expansion of the sample might be due to the elemental composition, particle size, green density, heating rate, and temperature of processing. However, the swelling effect can also be caused by the formation of $\mathrm{Fe}_{2} \mathrm{Al}_{5}$ compound [17]. There is a sudden rise in the volumetric expansion of the sample sintered at $900^{\circ} \mathrm{C}$ for $90 \mathrm{mins}$, which yielded the highest expansion, i.e. $16.04 \%$. The SEM image in Figure 3 shows vertical dark streaks along the sample indicated by the arrow, which are cracks induced during the sintering process. The high sintering temperature as well as the longer holding time allowed the sample to expand on a large scale, which in turn induced cracks in the sample [14]. This expansion might cause the initiation of cracks, which are visible in the micrograph shown in Figure 3.

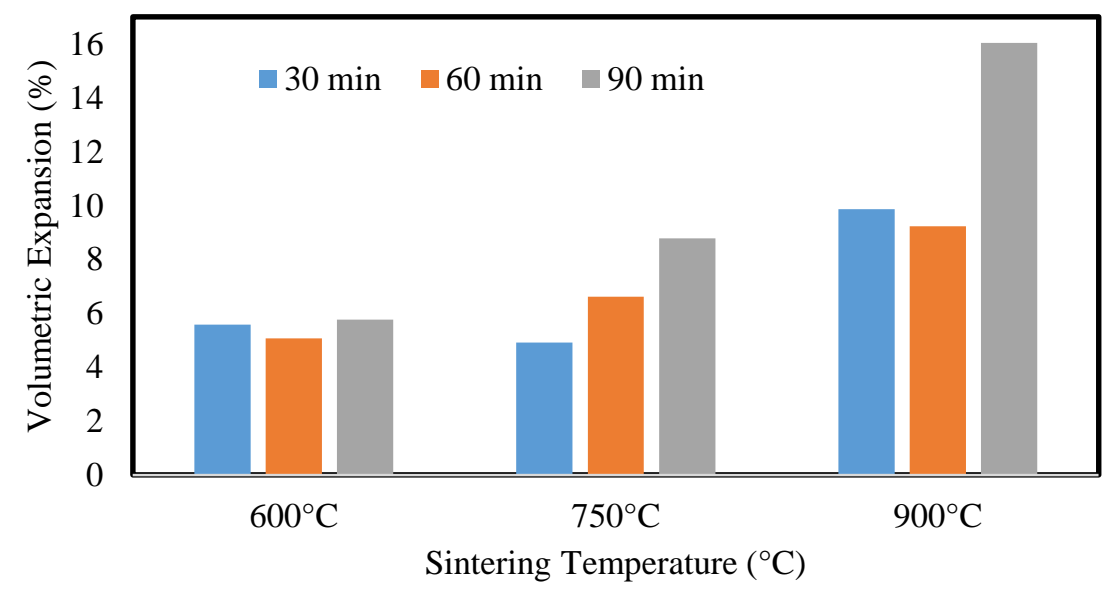

Figure 2. Volumetric expansion of FeCrAl compacts.

Figure 4 shows the changes in density between the green and the sintered samples. However, it was observed that, after sintering, the densities for all the samples declined. The highest density drop was for the sample sintered at $900^{\circ} \mathrm{C}$ for $30 \mathrm{mins}$, which yielded a decrease in density of $6.94 \%$. The sample sintered at $750^{\circ} \mathrm{C}$ for 30 mins attained the lowest density change, i.e., 3.18\%. The drop in density is the effect of volumetric expansion, which caused overall density changes showing a similar pattern to that of the volumetric expansion [17]. Sintering at high temperature for a long time means that the powder compacts are in a hot environment for a prolonged time, which could cause grain growth. The combined effects of grain growth and thermal expansion of metal powder particles cause the expansion of the products [29]. The drop in sintered density might be due to the volumetric expansion of the samples [30]. Since the density was measured 
based on the ratio between the mass and volume of each sample, a higher increase in volumetric expansion would produce a decline in the sintered density.

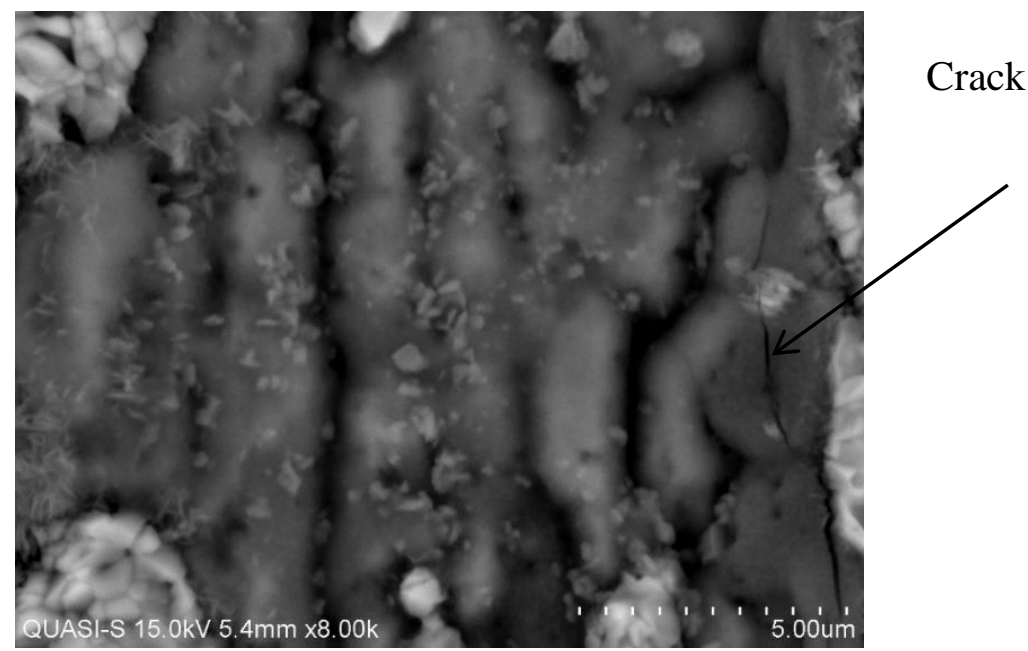

Figure 3. SEM image of sample sintered at $900^{\circ} \mathrm{C}$ for 90 mins.

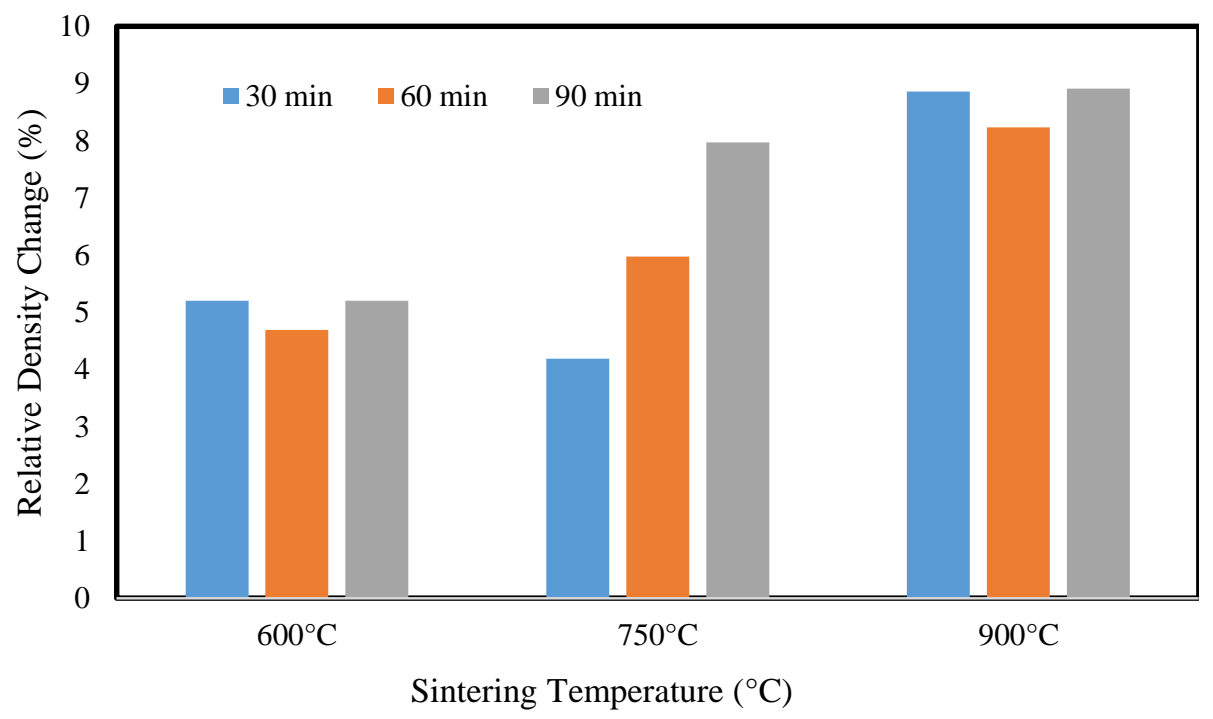

Figure 4. Relative density change from green to sintered.

The bending strength shown in Figure 5 is almost the inverse of the density changes (Figure 3) for the sample sintered at $750^{\circ} \mathrm{C}$, where the highest strength was obtained by the sample sintered at $900^{\circ} \mathrm{C}$ for 60 mins, which yielded a strength of 34.55 $\mathrm{MPa}$, and which also shows a lower density change (Figure 4) and volumetric expansion (Figure 2). Referring to the SEM image (Figure 6), it can be seen that the grains are closely packed together with fewer voids $[31,32]$. Close-packed grains might produce larger grain boundaries, which would further enhance the strength of the material. As for the samples sintered at $600^{\circ} \mathrm{C}$, the strength follows the same pattern as the drop in density, where the highest strength was obtained by the sample sintered for 90 mins. The samples sintered at $900^{\circ} \mathrm{C}$ show a similar trend to that of the samples sintered at $750^{\circ} \mathrm{C}$. However, there are some fluctuations when compared to the results of the density drop in Figure 3. The highest strength was obtained by the sample sintered for 60 mins. This particular 
sample also possesses the lowest density change for this batch. There are some fluctuations for the samples sintered for 30 mins and 90 mins. These fluctuations are caused by the cracks induced in the samples. The cracks result from the volumetric expansions, which in turn cause the formation of the $\mathrm{Fe}_{2} \mathrm{Al}_{5}$ compound, and other factors mentioned earlier.

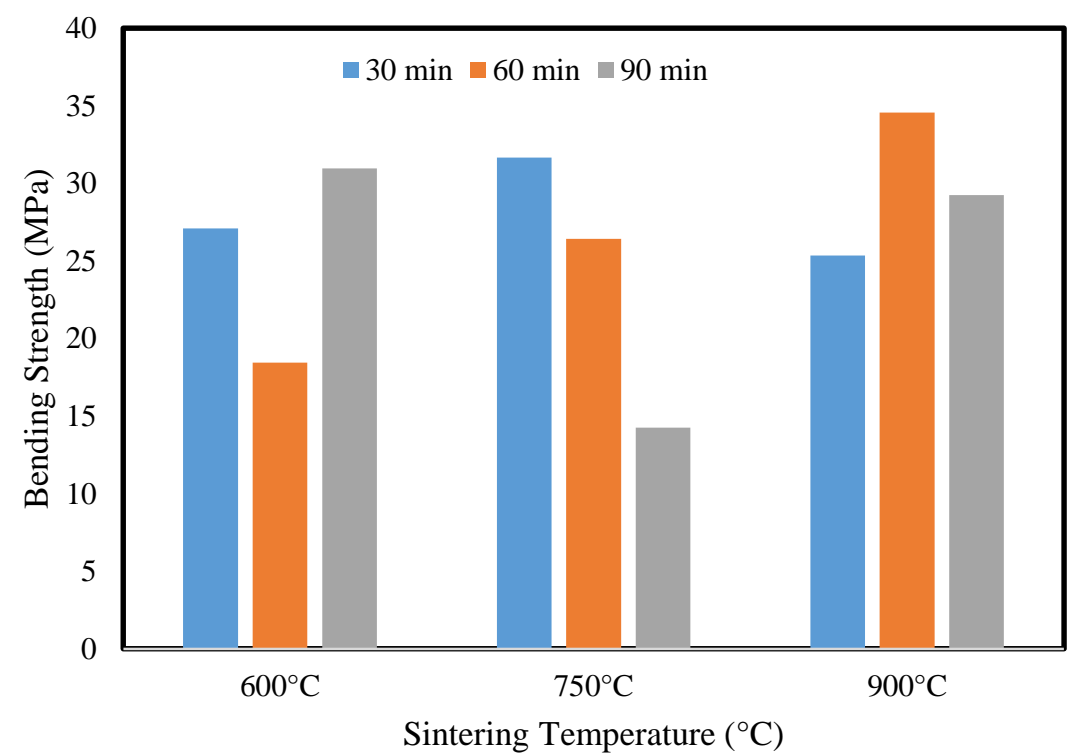

Figure 5. Bending strength of sintered FeCrAl compacts,

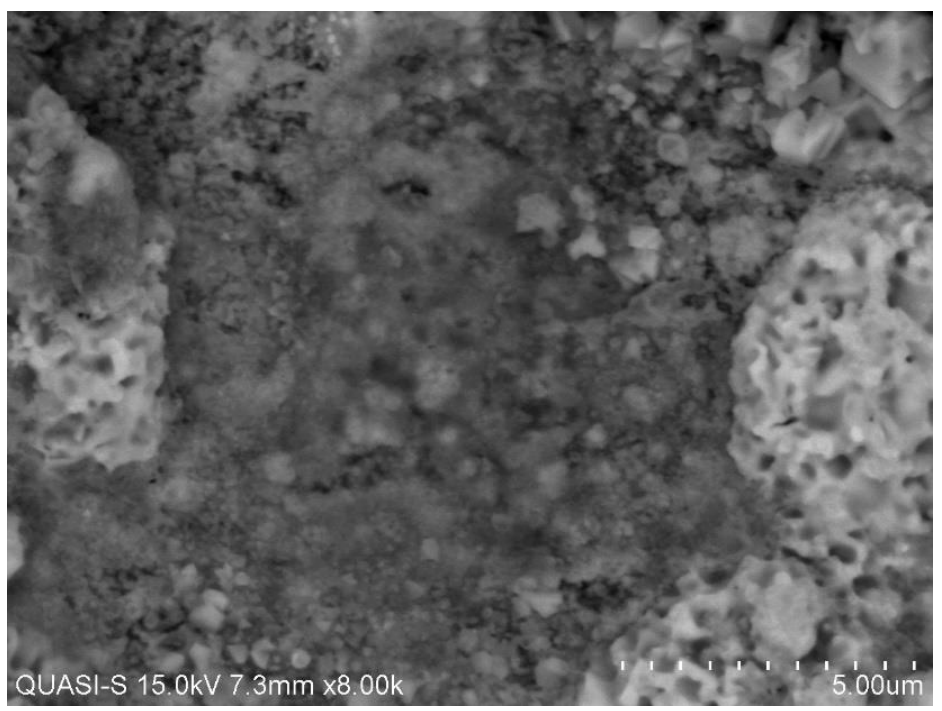

Figure 6. SEM image of $\mathrm{FeCrAl}$ compact sintered at $900^{\circ} \mathrm{C}$ for 60 mins.

It can be observed clearly in Figure 7(a) that the $\mathrm{Fe}, \mathrm{Cr}$ and $\mathrm{Al}$ elements are clustered together within their individual boundaries, which are represented in three different contrasts. The white area represents high concentrations of $\mathrm{Cr}$, while the dark grey and light grey areas represent high concentrations of $\mathrm{Fe}$ and $\mathrm{Al}$, respectively. However, as the holding time is prolonged, the grain boundaries are seen to disappear while forming distinctive structures, which can be observed in Figures 7(a) and 7(c). As a consequence of increasing the sintering temperature to $750^{\circ} \mathrm{C}$, the white grains are seen 
to dissolve into the grey grains, and with further increase of the holding time, new grain boundaries are formed (Figure 7(f)). However, when compared to the sample sintered at $600^{\circ} \mathrm{C}$ for 30 mins, a more dispersed pattern can be observed, with all the elements fused together. Also, the formation of new structures can be seen among the grain boundaries in the sample sintered at $750^{\circ} \mathrm{C}$ for 90 mins [33]. A good dispersion of elements can be seen in the samples sintered at $900^{\circ} \mathrm{C}$. No clustered region can be observed in this sample, although the holding time was prolonged. However, cracks are found propagating in the samples sintered for 60 mins and 90 mins (Figures 7(h) and 7(i)).
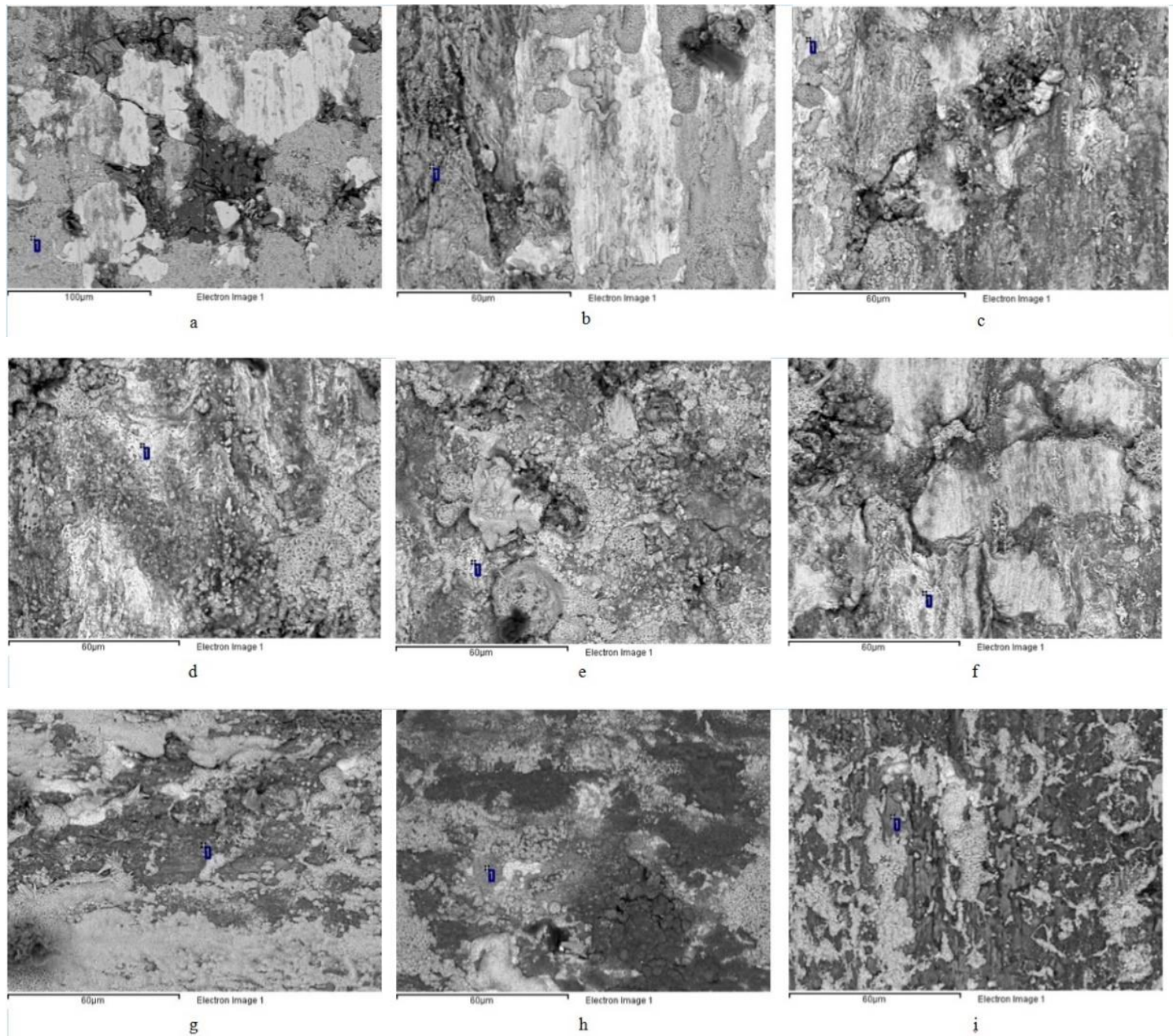

Figure 7. SEM images of FeCrAl compacts sintered at different schedules:

(a) $T=600^{\circ} \mathrm{C}, t=30 \mathrm{mins}$, (b) $T=600^{\circ} \mathrm{C}, t=60 \mathrm{mins}$, (c) $T=600^{\circ} \mathrm{C}, t=90 \mathrm{mins}$,

(d) $T=750^{\circ} \mathrm{C}, t=30 \mathrm{mins}$, (e) $T=750^{\circ} \mathrm{C}, t=60 \mathrm{mins}$, (f) $T=750^{\circ} \mathrm{C}, t=90 \mathrm{mins}$,

(g) $T=900^{\circ} \mathrm{C}, t=30 \mathrm{mins}$, (h) $T=900^{\circ} \mathrm{C}, t=60 \mathrm{mins}$, (i) $T=900^{\circ} \mathrm{C}, t=90 \mathrm{mins}$.

\section{CONCLUSIONS}

The sintering temperature and the holding time affected the volumetric expansion. As the sintering temperature increased, the volumetric expansion increased as well. The highest volumetric expansion was measured as $16.04 \%$ for the sample sintered at $900^{\circ} \mathrm{C}$ for 90 mins. The fluctuations in the volumetric expansion may be caused by the elemental composition, particle size and green density of the samples. The decline of the sintered 
density is believed to be caused by volumetric expansion, and the higher the volumetric expansion, the lower the sintered density. The highest density drop was measured as $6.94 \%$ in the sample sintered at $900^{\circ} \mathrm{C}$ for 30 mins. The bending strength was found to be inversely proportional to the change in density, where the higher change in density caused the sample to have lower strength. The highest bending strength was measured as $34.55 \% \mathrm{MPa}$ in the sample sintered at $900^{\circ} \mathrm{C}$ for $60 \mathrm{mins}$. However, the fluctuation in the results is caused by the cracks that propagated during the sintering process. The samples sintered at $750^{\circ} \mathrm{C}$ and $900^{\circ} \mathrm{C}$ show a better dispersion of the alloyed elements than in the samples sintered at $600^{\circ} \mathrm{C}$, although there is formation of cracks at the sintering temperature of $900^{\circ} \mathrm{C}$. The sample sintered at $900^{\circ} \mathrm{C}$ for 60 mins shows the best result when compared to the other sintering schedules. Therefore, sintering of warm formed powder mass, when conducted at a moderately high temperature for a medium duration of time, is found to produce a sintered product with higher density, lower volumetric expansion, greater strength and a better microstructure. Further study considering different sintering rates and higher sintering temperatures is recommended.

\section{ACKNOWLEDGEMENTS}

The authors want to thank the Ministry of Higher Education (MOHE), Malaysia for funding this research study under 20140117 FRGS. Gratitude to Universiti Tenaga Nasional for permitting the authors to use the lab facilities through out this research project.

\section{REFERENCES}

[1] Yan W, Pun C. Spherical indentation method to measure mechanical properties of metallic foams. Materials Research Innovations. 2011;15:s41-s4.

[2] Rahman MM, Yogaswerarow S. Effects of compaction and sintering temperature to the alloyability of $\mathrm{FeCrCu}$ powder mixture. Advanced Materials Research: Trans Tech Publ; 2016. p. 264-8.

[3] Sharma D, Chandra K, Misra PS. Design and development of powder processed Fe-P based alloys. Materials \& Design. 2011;32:3198-204.

[4] Odusote J, Adeleke A, Ajayi P. Mechanical properties and microstructure of precipitation-hardened $\mathrm{Al}-\mathrm{Cu}-\mathrm{Zn}$ alloys. International Journal of Automotive and Mechanical Engineering. 2015;12.

[5] Callister WD, Rethwisch DG. Materials science and engineering: an introduction: Wiley New York; 2007.

[6] Lobb R, Jones R. Creep-rupture properties of fecralloy stainless steel between 650 and $800^{\circ}$ c. Journal of Nuclear Materials. 1980;91:257-64.

[7] Wang T, Yao S, Shen W. A submerged-gate casting method. Journal of Materials Processing Technology. 2015;222:21-6.

[8] Jiang X, Trunov MA, Schoenitz M, Dave RN, Dreizin EL. Mechanical alloying and reactive milling in a high energy planetary mill. Journal of Alloys and Compounds. 2009;478:246-51.

[9] Sonsino C, Ratzi R. Warm powder compaction substitutes conventionally double pressed and double sintered synchroniser hubs. Powder metallurgy. 2004;47:3527. 
[10] Ariffin A, Rahman MM, Muhamad N, Sahari J. Thermal-mechanical model of warm powder compaction process. Journal of Materials Processing Technology. 2001;116:67-71.

[11] Rahman M, Ariffin A, Nor S, Rahman H. Powder material parameters establishment through warm forming route. Materials \& Design. 2011;32:264-71.

[12] Rahman M, Wardi M, Nor S. On the effect of feedstock preparation on the characteristics of warm formed powder compacts. International Journal of Automotive and Mechanical Engineering. 2013;8:1132.

[13] Rahman M, Nor S. An experimental investigation of metal powder compaction at elevated temperature. Mechanics of Materials. 2009;41:553-60.

[14] Rahman M, Nor S, Rahman H. Effects of lubrication in warm powder compaction process. ASM Science Journal. 2011; 5(1):18.

[15] Herrmann J, Inden G, Sauthoff G. Deformation behaviour of iron-rich ironaluminum alloys at low temperatures. Acta Materialia. 2003;51:2847-57.

[16] Gökçe A, Fındık F, Kurt AO. Microstructural examination and properties of premixed $\mathrm{Al}-\mathrm{Cu}-\mathrm{Mg}$ powder metallurgy alloy. Materials Characterization. 2011;62:730-5.

[17] Kang H-Z, Hu C-T. Swelling behavior in reactive sintering of Fe-Al mixtures. Materials Chemistry and Physics. 2004;88:264-72.

[18] Zhou Y, Zuo X, Sun J, Mei J, Sun J. Effects of sintering parameters on the structures of $\mathrm{Fe}-\mathrm{Cr}-\mathrm{Al}$ extruded honeycombs. Materials Science and Engineering: A. 2007;457:329-33.

[19] Rahman MM, Talib A. Effect of sintering schedule to the alloyability of FeCrAl powder mix formed at above ambient temperature. Advanced Materials Research: Trans Tech Publ; 2015. p. 199-202.

[20] Rahman M, Rahman H, Zabri NH. Characteristics of FeCuAl powder compacts sintered at different schedules. Scientific Journal of PPI-UKM. 2015;2:108-11.

[21] Rahman MM, Tarlochan F, Singh R, Ariffin AK, Nor S. Numerical simulation and experimentation of warm metal powder compaction process. Key Engineering Materials: Trans Tech Publ; 2011. p. 704-9.

[22] Rahman MM, Nor A. Effect of feedstock preparation and forming temperature to the characteristics of green compacts. Advanced Materials Research: Trans Tech Publ; 2014. p. 245-50.

[23] Rutz H, Hanejko F. High density processing of high performance ferrous materials. Advances in Powder Metallurgy and Particulate Materials. 1994;5:117-

[24] Nor S, Rahman MM, Rahman A, Tarlochan F, Rahman H. A parametric analysis of the strength-porosity relationship of green compacts formed through powder compaction route. Applied Mechanics and Materials: Trans Tech Publ; 2011. p. $1-6$.

[25] Nor S, Rahman M, Tarlochan F, Shahida B, Ariffin A. The effect of lubrication in reducing net friction in warm powder compaction process. Journal of Materials Processing Technology. 2008;207:118-24.

[26] German R. Sintering: from empirical observations to scientific principles: Butterworth-Heinemann; 2014.

[27] German RM, Bose A. Injection molding of metals and ceramics: Metal Powder Industries Federation; 1997.

[28] Chew WJK NA, Nawawi NA, Bang LT, Ramesh S. Influence of powder morphology and sintering temperature on the properties of hydroxyapatite. 
International Journal of Automotive and Mechanical Engineering. 2015;12:308996.

[29] Fang ZZ, Wang H. Densification and grain growth during sintering of nanosized particles. International Materials Reviews. 2008;53:326-52.

[30] Kelvin H, Ramesh S, Tanand CY, Teng WD. Phase analysis and densification of steatite-based ceramics. International Journal of Automotive and Mechanical Engineering. 2010;1:38-45.

[31] Sakinah M, Amirruddin A, Kadirgama K, Ramasamy D, Rahman M, Noor M. The application of response surface methodology in the investigation of the tribological behavior of palm cooking oil blended in engine oil. Advances in Tribology. 2016;2016.

[32] Najiha M, Rahman M, Kadirgama K, Noor M, Ramasamy D. Multi-objective optimization of minimum quantity lubrication in end milling of aluminum alloy AA6061T6. International Journal of Automotive \& Mechanical Engineering. $2015 ; 12$.

[33] Muthusamy Y, Kadirgama K, Rahman M, Ramasamy D, Sharma K. Wear analysis when machining AISI 304 with ethylene glycol/TIO2 nanoparticle-based coolant. The International Journal of Advanced Manufacturing Technology. 2016;82:327-40. 